\title{
Thermogravimetric study of the reduction of basic lead sulphate
}

\author{
Stanisław Małecki
}

Received: 7 October 2013/ Accepted: 8 May 2014/Published online: 10 June 2014

(c) The Author(s) 2014. This article is published with open access at Springerlink.com

\begin{abstract}
In this paper, the results of the study of the reduction of basic lead sulphate with a gas $\left(\mathrm{CO}+\mathrm{CO}_{2}\right)$ mixture are presented. This is a secondary reaction during the reduction of lead sulphate. The change in the both lead and $\mathrm{PbS}$ content in the reaction products, depending on the process temperature and the composition of the gaseous phase, was established. The comparison of the rate of the reduction reaction of lead sulphate and basic lead sulphate shows that the process proceeding with a higher output is the reduction of basic lead sulphate.
\end{abstract}

Keywords Reduction - Basic lead sulphate ·

Thermogravimetric analysis $\cdot$ Kinetics

\section{Introduction}

This article is a piece of research on the reduction of metal sulphates. In the literature, this problem is quite simply treated. Only the authors [1] represent research of reduction by $\mathrm{CO}$. They concern the reduction of magnesium sulphate. The results of the metal sulphates reduction by hydrogen were presented in the papers $[2,3]$. The authors indicate the reduction temperature range and resulting products in these temperatures. However, these results are a qualitative rather, without going into the chemical and phase composition of the process products. Vijh [4] presents an analysis of the sulphate reduction temperature dependence of the selected physicochemical parameters.

S. Małecki $(\bowtie)$

Faculty of Non-Ferrous Metals, AGH University of Science and Technology, 30 Mickiewicza Av, 30-059 Kraków, Poland

e-mail: stanmal@agh.edu.pl
The study presented here is a continuation of the study of the reduction of the lead sulphate. The results of the previous study [5] concerning the reduction of lead sulphate $\mathrm{PbSO}_{4}$ shows that the first process is the formation of lead sulphide which then reacts at the interface of the phases with the sulphate. The range of the temperatures (893-1,073 K) for which the lead sulphate reduction was conducted suggests that for the reaction between the original product, i.e. $\mathrm{PbS}$, and $\mathrm{PbSO}_{4}$ a basic lead sulphate $\mathrm{PbO} \cdot \mathrm{PbSO}_{4}$ should be formed [6]. Then, this product will undergo further reduction and in the result the metallic lead and lead sulphide will be formed. Therefore, the reaction scheme of this process will have the following form:

$\mathrm{PbSO}_{4} \rightarrow \mathrm{PbS}, \mathrm{PbSO}_{4} \rightarrow \mathrm{PbO} \cdot \mathrm{PbSO}_{4} \rightarrow \mathrm{Pb}, \mathrm{PbS}$

The aim of this study is to determine whether the basic lead sulphate reduction is the fast process and can be one of the stages of sulphate reduction.

\section{Methodology of the study}

The study of the reduction of basic lead sulphate $\mathrm{PbO} \cdot \mathrm{PbSO}_{4}$ was preceded by making this substrate. The basic sulphate was obtained by the sintering the mixture of lead oxide and lead sulphate of 1:1 mol ratio. The sintering process was conducted in an inert gas atmosphere in the temperature range of $723-773 \mathrm{~K}$ for $24 \mathrm{~h}$. Then, the material was ground, mixed and sintered again for the same time. The sintering process was repeated three times. The obtained preparation was subjected to the X-ray phase analysis and chemical analysis. The results of the phase analysis showed the occurrence only of basic lead sulphate $\mathrm{PbO} \cdot \mathrm{PbSO}_{4}$. The chemical analysis revealed that the lead content level was 78.52 mass \%, and sulphur in sulphate 


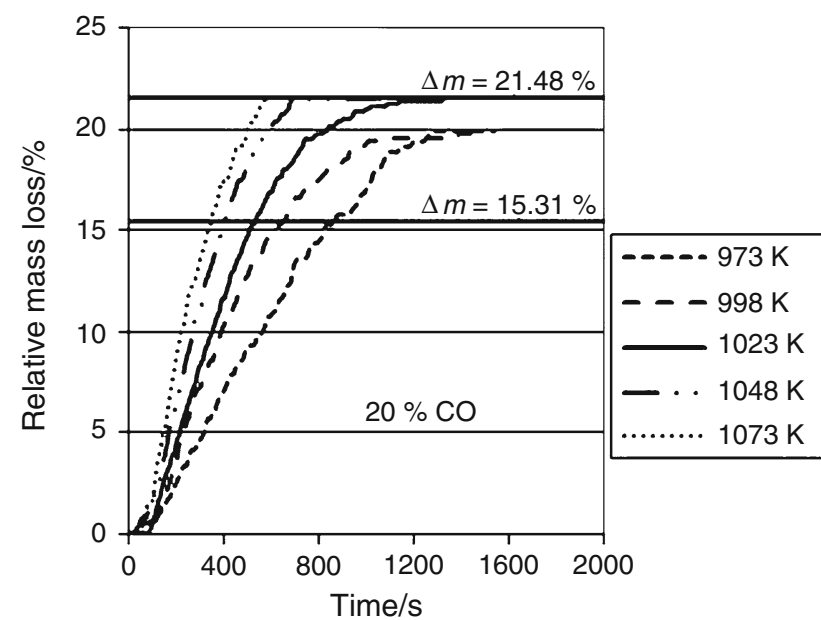

Fig. 1 The change in the relative mass loss of the $\mathrm{PbO} \cdot \mathrm{PbSO}_{4}$ sample during the process of reduction with the gas containing $20 \%$ of $\mathrm{CO}$ and $80 \%$ of $\mathrm{CO}_{2}$ in different temperatures

form 6.17 mass \%. This corresponds to the mixture $0.967 \mathrm{PbO} \cdot \mathrm{PbSO}_{4}$, which means that a small excess of $\mathrm{PbSO}_{4}$ occurs in the preparation.

The isothermal study of the reduction of the basic lead sulphate was conducted using the thermogravimetric method on a powder preparation placed on a ceramic pan suspended to an electronic scale connected with computer and recording the change in the mass with the accuracy of $1 \times 10^{-3} \mathrm{~g}$. The sample mass in each measurement was $0.750 \mathrm{~g}$. Before the measurement starting system was being purged of air by passing the mixture $\left(\mathrm{CO}+\mathrm{CO}_{2}\right)$. The sample is placed in an electric resistance furnace which was heated to the desired temperature. From the bottom of the furnace, the $\mathrm{CO}+\mathrm{CO}_{2}$ gas mixture of a specific composition was fed. The gas mixture was controlled by rotameters. The stream of flowing gases was selected so that it did not affect the process rate and it was $60 \mathrm{dm}^{3} \mathrm{~h}^{-1}$. The temperature in the furnace was controlled by a Pt-RhPt thermocouple placed directly underneath the tested sample. Due to the small mass of the sample and the measuring vessel, heating time of the sample to the isothermal temperature in each case was similar and should not have a significant impact on results. The process duration was measured from the time the sample was placed into the furnace until the sample mass stabilised as constant. The investigations were conducted in the temperature range of $893-1,073 \mathrm{~K}$ (interval of $25^{\circ}$ ) with a varying $\mathrm{CO}$ content in the gas mixture in the range of $20-100 \%(20,50,70$ and $100 \%)$. Each measurement was repeated three times and the results were averaged. It should be noted that under the conditions of the process evaporation of metallic lead formed is negligible.

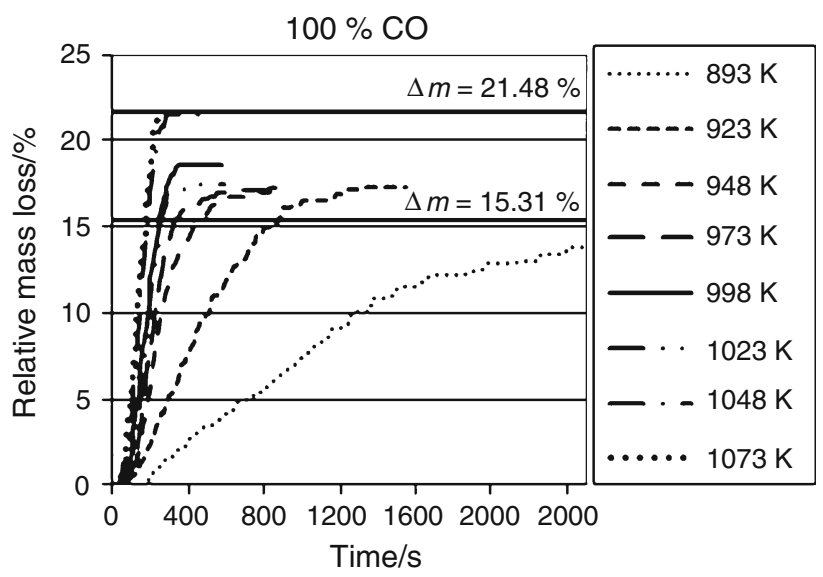

Fig. 2 The change in the relative mass loss of the $\mathrm{PbO} \cdot \mathrm{PbSO}_{4}$ sample during the process of reduction with the gas containing $100 \%$ of $\mathrm{CO}$ in different temperatures

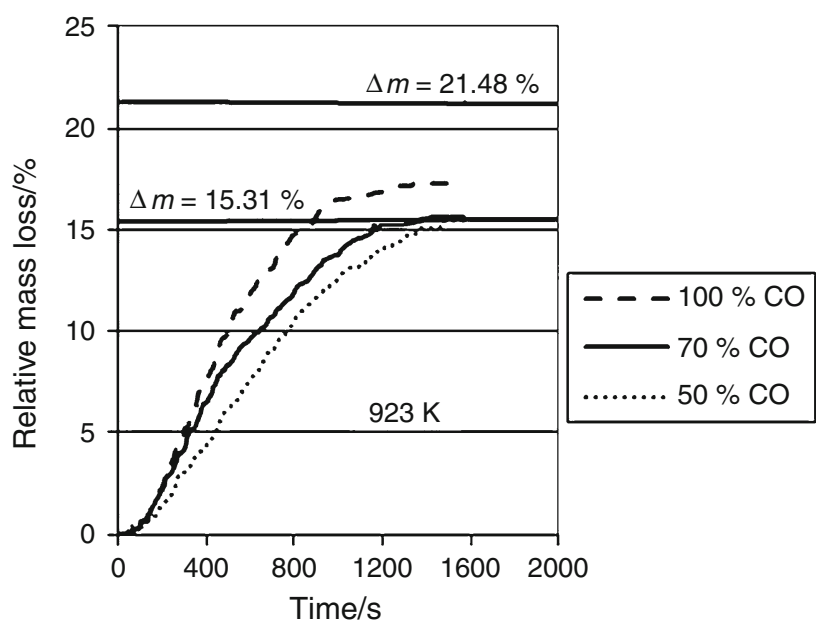

Fig. 3 The change in the relative mass loss of the $\mathrm{PbO} \mathrm{PbSO}_{4}$ sample during the process of reduction with the gas containing varying amounts of $\mathrm{CO}$ in the temperature of $923 \mathrm{~K}$

\section{Experimental}

The changes in the mass of the samples recorded in the experiments allowed to calculate the relative mass change which is presented in Figs. 1-4 for selected process parameters. Since the X-ray phase analysis of the products showed the occurrence of only the lead sulphate and metallic lead in those products, therefore, on the graphs the relative mass loss was marked which the sample should have reached if the final summary product of the reaction was only lead or $\mathrm{PbS}$ from the $\mathrm{PbSO}_{4}$ reduction (the sum of $\Delta m$ from the reactions 1 and 2) and $\mathrm{Pb}$ from the $\mathrm{PbO}$ reduction ( $\Delta m$ from the reaction 3 ).

The presented dependency and results of phase analysis show that during the reduction of $\mathrm{PbO} \cdot \mathrm{PbSO}_{4}$ the following 


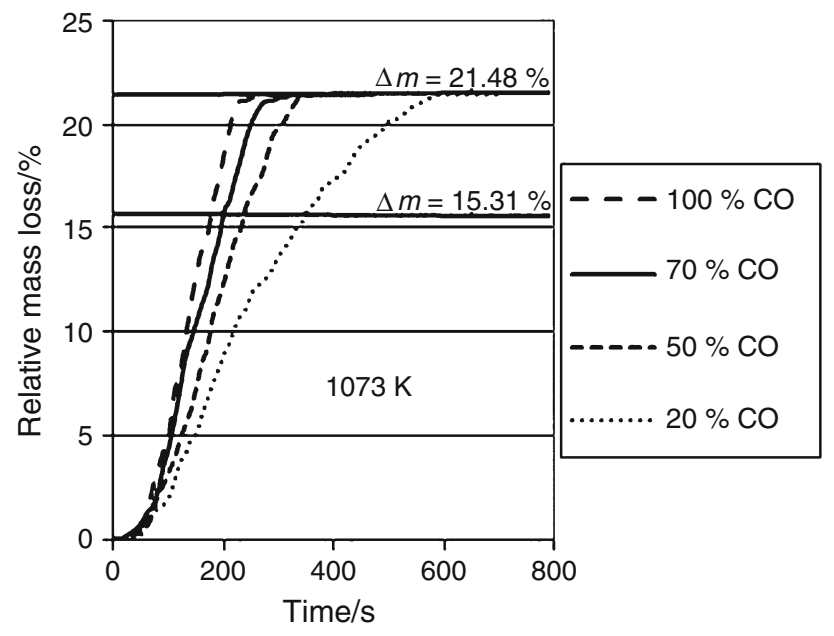

Fig. 4 The change in the relative mass loss of the $\mathrm{PbO} \cdot \mathrm{PbSO}_{4}$ sample during the process of reduction with the gas containing varying amounts of $\mathrm{CO}$ in the temperature of $1,073 \mathrm{~K}$

reaction may proceed with the corresponding mass changes:

$\mathrm{PbO}+\mathrm{CO}=\mathrm{Pb}+\mathrm{CO}_{2} \quad \Delta m=2.98 \%$

$\mathrm{PbSO}_{4}+4 \mathrm{CO}=\mathrm{PbS}+4 \mathrm{CO}_{2} \quad \Delta m=12.33 \%$

$\mathrm{PbO} \cdot \mathrm{PbSO}_{4}+3 \mathrm{CO}=2 \mathrm{~Pb}+3 \mathrm{CO}_{2}+\mathrm{SO}_{2}$ $\Delta m=21.48 \%$

Therefore, it can be assumed that in the initial period of the reaction, alkaline sulphate behaves as a mixture of oxide and sulphate.

\section{Results and discussion}

The analysis of the presented relationships shows that with the constant composition of the gaseous phase, the increase of temperature causes the increase of the metallic lead content in the reaction products. With the content of $\mathrm{CO}$ in the gaseous phase amounting to 50,70 and $100 \%$, it can be observed that from $1,048 \mathrm{~K}$ the temperature increase does not significantly affect the reaction rate any longer. At the same time, with those process parameters only lead is present in the reaction products.

More complicated relationship is observed during the analysis of the graphs for constant temperature and for different gaseous phase compositions. Despite the increasing rate of the processes with the increase of the $\mathrm{CO}$ content in the reductive gas, the final composition of the reaction products depends on the temperature. In lower temperatures, along with the higher share of $\mathrm{CO}$ in the flowing gas, the quantity of the metallic lead in the process products increases. Within the

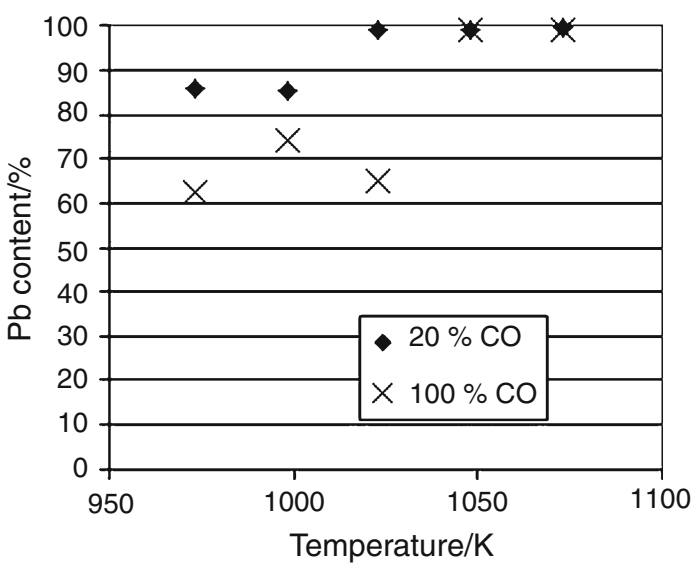

Fig. 5 The relationship between the lead content as a function of temperature for the 20 and $100 \% \mathrm{CO}$ concentration in the gaseous phase

temperature range of $973-1,023 \mathrm{~K}$, this relation is inverse, and then in higher temperatures only lead in the metallic form is present in the products. The relationship presented in Fig. 2 is noteworthy. It shows that with $100 \% \mathrm{CO}$ concentration in the gaseous phase in the temperature of $893 \mathrm{~K}$, the reduction reaches the level of the relative change in the mass corresponding to the reduction of $\mathrm{PbO}$ to $\mathrm{Pb}$, and $\mathrm{PbSO}_{4}$ to $\mathrm{PbS}$. In this temperature, there is practically no reaction between $\mathrm{PbS}$ and $\mathrm{PbSO}_{4}$, which is in conformity with the results of the study [6]. Then, in higher temperatures, the process ends with the same product composition and only from the temperature of 1,048 $\mathrm{K}$ up metallic lead is obtained. In Fig. 5, the change of the lead content in the reaction products depending on the process temperature for two different $\mathrm{CO}$ concentrations in the gaseous phase is presented. The higher share of the sulphide in the reaction products in lower temperatures results from the low rate of the after-reaction between lead sulphide and lead sulphate [7]. With the increase of the rate of this after-reaction also the share of metallic lead in the products increases. However, a low $\mathrm{CO}$ concentration in the gaseous phase radically decreases the rate of the reduction of lead sulphate. Nevertheless, the reaction between the sulphide and sulphate (consecutive reaction) leads to the relatively significant increase of the metallic lead content in the reaction products.

The obtained values of the relative mass changes were converted into the extent of reaction, assuming that the final reaction product is metallic lead only. Then, the obtained values were described with the kinetic equation in the form [8]:

$1-(1-\alpha)^{2 / 3}=k \cdot t+A$

where $\alpha$ is the extent of reaction, $k$ is the constant proportional to the reaction rate $\left(\mathrm{s}^{-1}\right), t$ is the process duration (s), and $A$ is the initial ordinate. 
Table 1 The values of the parameters of the kinetic equation

\begin{tabular}{|c|c|c|c|c|}
\hline $\begin{array}{l}\text { Temperature/ } \\
\mathrm{K}\end{array}$ & $\begin{array}{l}\mathrm{CO} \\
\text { concentration } \\
\text { in the gaseous } \\
\text { phase } / \%\end{array}$ & $\begin{array}{l}\text { Constant } \\
k / \mathrm{s}^{-1}\end{array}$ & $\begin{array}{l}\text { Starting } \\
\text { ordinate } \\
A\end{array}$ & $\begin{array}{l}\text { Square of the } \\
\text { correlation } \\
\text { coefficient } \\
R^{2}\end{array}$ \\
\hline \multirow[t]{3}{*}{923} & 50 & 0.0005 & -0.0407 & 0.9928 \\
\hline & 70 & 0.0006 & -0.0184 & 0.9865 \\
\hline & 100 & 0.0008 & -0.0706 & 0.9935 \\
\hline \multirow[t]{3}{*}{948} & 50 & 0.0008 & -0.0919 & 0.9939 \\
\hline & 70 & 0.0014 & -0.1496 & 0.9954 \\
\hline & 100 & 0.002 & -0.2013 & 0.9851 \\
\hline \multirow[t]{4}{*}{973} & 20 & 0.0007 & -0.0581 & 0.9982 \\
\hline & 50 & 0.0013 & -0.1242 & 0.9964 \\
\hline & 70 & 0.0019 & -0.1618 & 0.9981 \\
\hline & 100 & 0.0026 & -0.2436 & 0.9925 \\
\hline \multirow[t]{4}{*}{998} & 20 & 0.0011 & -0.0801 & 0.9957 \\
\hline & 50 & 0.0023 & -0.2355 & 0.9971 \\
\hline & 70 & 0.0022 & -0.1204 & 0.9936 \\
\hline & 100 & 0.0034 & -0.2896 & 0.9971 \\
\hline \multirow[t]{4}{*}{1,023} & 20 & 0.0013 & -0.1094 & 0.9994 \\
\hline & 50 & 0.002 & -0.1763 & 0.9992 \\
\hline & 70 & 0.0027 & -0.2026 & 0.9982 \\
\hline & 100 & 0.0034 & -0.3181 & 0.9946 \\
\hline \multirow[t]{4}{*}{1,048} & 20 & 0.0018 & -0.1386 & 0.9988 \\
\hline & 50 & 0.0037 & -0.3177 & 0.9947 \\
\hline & 70 & 0.0038 & -0.2676 & 0.9984 \\
\hline & 100 & 0.0052 & -0.4065 & 0.9988 \\
\hline \multirow[t]{4}{*}{1,073} & 20 & 0.0021 & -0.1292 & 0.9937 \\
\hline & 50 & 0.0037 & -0.2980 & 0.9980 \\
\hline & 70 & 0.0045 & -0.3175 & 0.9951 \\
\hline & 100 & 0.0059 & -0.4386 & 0.9937 \\
\hline
\end{tabular}

This equation was selected from many known so as to best describe the measurement points. The aim of the kinetics analysis was to determine the activation energy of the process and the appointment of constants proportional to the process rate for comparison with the rate of $\mathrm{PbSO}_{4}$ reduction. Since the kinetic model was selected on the basis of statistical and it describes a multistage process it has no physical meaning.

In Table 1, the compilation of the values of kinetic equations parameters for various process conditions is presented, and in Fig. 6 the conformity of the experimental points with the mathematical description is shown as an example. In the description, the start and the end points of the measurement were skipped. Outside of these narrow ranges, the proposed equation correctly describes the experimental results.

Using the Arrhenius relationship and the data compiled in Table 1, the energy of the process activation was determined. It amounts to $101 \pm 8 \mathrm{~kJ} \mathrm{~mol}^{-1}$, and does not

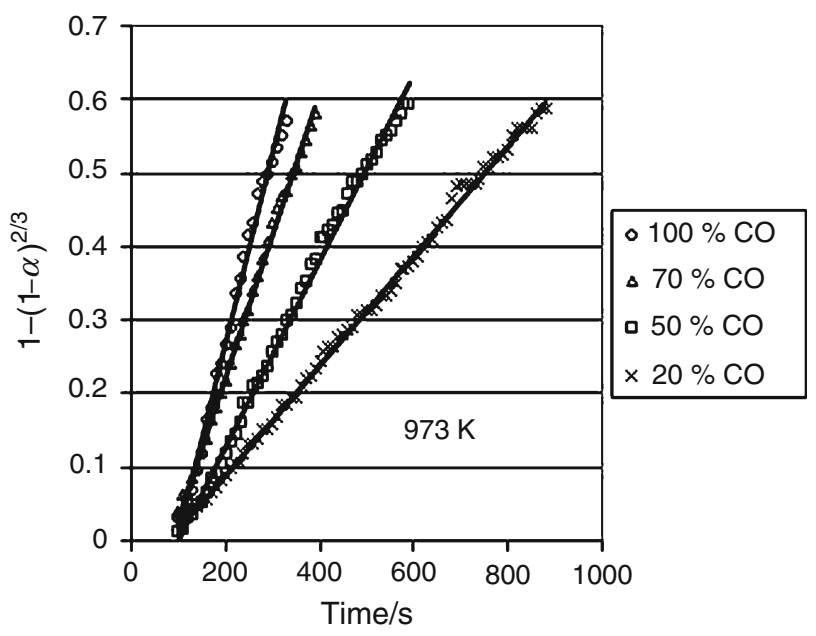

Fig. 6 The conformity of the description according to the kinetic equation with the experimental data for the temperature of $973 \mathrm{~K}$

depend on the gaseous phase composition. This value may suggest that the process rate is limited by a chemical process.

\section{Summary}

The analysis of the processes of the reduction of metal sulphates with a gaseous reducing agent leads to the conclusion that sulphide is always the original product of this reaction. Lead is produced by secondary reactions. The lead content in the reaction products increases with temperature and with decreasing $\mathrm{CO}$ concentration in the gaseous phase. The final composition of the products depends on the rate of secondary reactions. The problem of the reduction of basic lead sulphate being undertaken in this study results from the fact that this reaction may be decisive to a significant extent for the final composition of the product of the lead sulphate reduction.

During the reduction of lead sulphate within the temperature range being investigated the following reactions may take place:

$\mathrm{PbSO}_{4}+4 \mathrm{CO}=\mathrm{PbS}+4 \mathrm{CO}_{2}$

$\mathrm{PbS}+7 \mathrm{PbSO}_{4}=4\left(\mathrm{PbO} \cdot \mathrm{PbSO}_{4}\right)+4 \mathrm{SO}_{2}$

$\mathrm{PbO} \cdot \mathrm{PbSO}_{4}+5 \mathrm{CO}=\mathrm{Pb}+\mathrm{PbS}+5 \mathrm{CO}_{2}$

At the moment when minimum sulphide amounts appear, the reaction (5) starts resulting in the formation of basic lead sulphate. Only as the result of the reaction (6) metallic lead is formed. The mutual relations between the rates of these processes are decisive for the final composition of the products. In Fig. 7, the comparison of the values of the constants proportional to the rate of the reactions for the processes (4) and (6) is presented. 


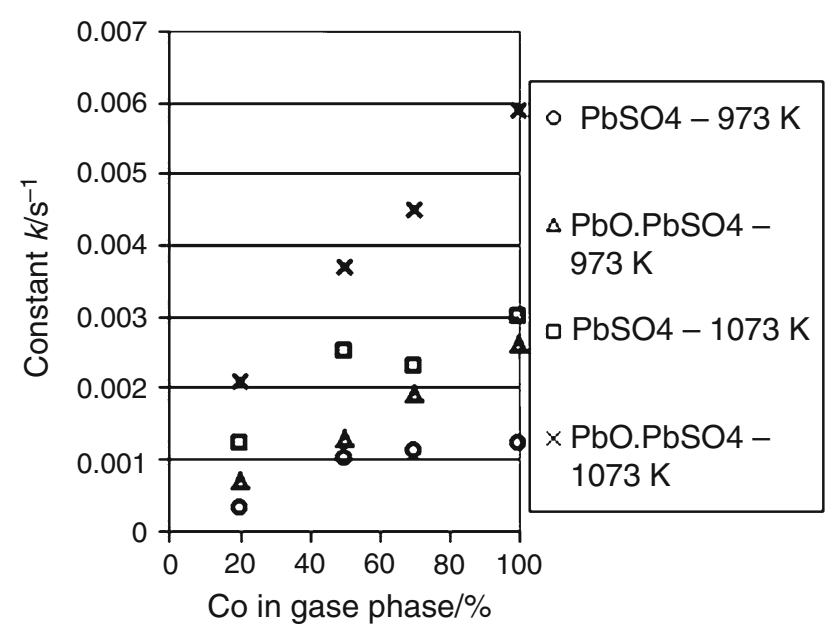

Fig. 7 The comparison of the constants proportional to the rate of the reaction for the lead sulphate reduction [9] and basic lead sulphate reactions in various process conditions

The presented relationships show a higher rate of the after-reaction course, i.e. the reaction of the reduction of basic lead sulphate. The differences in the reaction rates increase with the increase of temperature and the $\mathrm{CO}$ concentration in the gaseous phase. The analysis of the results of the investigation of the reduction of both lead sulphate and basic lead sulphate and the reaction between $\mathrm{PbS}$ and $\mathrm{PbSO}_{4}[6]$ provides the basis for the assertion that the metal formed in the products of the sulphate reduction is the consequence of the reaction proceeding between sulphide and sulphate. Due to this, basic lead sulphates appear with the increasing temperature share of $\mathrm{PbO}$, which is being reduced to metallic lead.

Open Access This article is distributed under the terms of the Creative Commons Attribution License which permits any use, distribution, and reproduction in any medium, provided the original author(s) and the source are credited.

\section{References}

1. Plewa J, Steindor J. Kinetics of reduction of magnesium sulfate by carbon oxide. J Therm Anal. 1987;32:1809-20.

2. Habashi F, Mikhail SA, Kim VV. Reduction of sulfates by hydrogen. Can J Chem. 1976;54:3646-50.

3. Habashi F, Mikhail SA. Reduction of binary sulfate mixtures containing $\mathrm{CuSO}_{4}$ by $\mathrm{H}_{2}$. Can J Chem. 1976;54:3651-7.

4. Vijh AK. A thermochemical approach to the gas-phase reduction of metal sulphates. J Mater Sci. 1978;13:2413-7.

5. Malinowski C, Małecki S, Żołnierczyk D. Reduction of $\mathrm{PbSO}_{4}$ by $\left(\mathrm{CO}+\mathrm{CO}_{2}\right)$ mixture. Thermochim Acta. 2004;423(1-2):143-8.

6. Malinowski C, Malinowska K. Analysis of the chemical reaction between $\mathrm{PbS}$ and $\mathrm{PbSO}_{4}$ and $\mathrm{ZnSO}_{4}$ on the basis of thermogravimetric investigations (in Polish). ZN AGH Metalurgia i Odlewnictwo Kraków. 1987;1138(109):113-24.

7. Malinowski C. Analysis of the chemical reaction between $\mathrm{PbSO}_{4}$ and PbS. Thermochim Acta. 1987;119:329-36.

8. Malinowski C. Analysis of the effects of time factors of the oxidation rate of zinc sulphide. Arch Metall. 1983;28:193-207.

9. Żołnierczyk D. Effect of the temperature and $\mathrm{CO}$ concentration in the gaseous phase $\left(\mathrm{CO}-\mathrm{CO}_{2}\right)$ on the rate of $\mathrm{PbSO}_{4}$ reduction (in Polish). Msc. Thesis. AGH Kraków. 2002. 